\title{
A INDISPONIBILIDADE DO BEM JURÍDICO VIDA E O DIREITO DE MORRER DIGNAMENTE
}

\section{THE UNAVAILABILITY LEGAL GOOD LIFE AND THE RIGHT TO DIE WORTHILY}

Fernando Tadeu Marques ${ }^{1}$

Amanda Gurzone Tessaro ${ }^{2}$

\section{Resumo}

O presente artigo expõe o estudo acerca da Eutanásia, exibindo o conceito, a evolução histórica sobre o procedimento e suas classificações. Tem como objetivo demonstrar a legalidade da prática desse método para assegurar à pessoa o exercício dos direitos fundamentais, uma vez que, o ordenamento jurídico brasileiro não permite esse procedimento, tanto no atual Código Penal brasileiro, quanto no Anteprojeto do Novo Código Penal. Por meio desse estudo foi desempenhada a análise de casos concretos, dos cuidados paliativos como alternativa e das legislações atinentes. Retrata sobre a indisponibilidade do bem jurídico vida. Apresenta o direito ao testamento vital e sua implantação. Por fim, discorre sobre o direito à morte digna, exercendo autonomia sobre a própria vida. Desse modo, este presente estudo teve por resultado que, a legalização da eutanásia é necessária para garantir ao indivíduo a liberdade de escolha em realizar este procedimento e que seja realizado de um modo seguro com respaldo em lei.

Palavras-chave: Eutanásia; Direitos fundamentais; Indisponibilidade do bem jurídico vida; Morte digna.

\footnotetext{
1 Professor, Advogado Criminalista. Doutorando em Direito e Mestre em Direito Penal pela Pontifícia Universidade Católica de São Paulo. Especialista pela Escola Paulista de Direito em Direito Público. Especialista pela Faculdade Anchieta em Docência no Ensino Superior. Bacharel em Direito pela Universidade Paulista. Exerce atividade docente como professor na graduação em Direito da Pontifícia Universidade Católica de de Campinas (SP) e na pós-graduação de Direito Penal e Processo Penal da Pontifícia Universidade Católica de Poços de Caldas (MG); leciona na Escola Paulista de Direito (EPD) a disciplina Direito Penal Médico no Curso de pós-graduação de Direito Médico e Hospitalar; É Membro avaliador de artigos científicos na Universidade Central do Chile, na Universidade Federal de Santa Maria e no Instituto Brasileiro de Ciências Criminais. Integra como pesquisador na Universidade Federal de São Paulo (UNIFESP) o Grupo de Pesquisa Conflitos armados, massacres e genocídios na era contemporânea. É coordenador adjunto no IBCCRIM. E-mail: profmarquespesquisa@gmail.com

${ }^{2}$ Graduanda em Direito pela Universidade Presbiteriana Mackenzie.
} 


\begin{abstract}
The present article presents the study about Euthanasia, showing the concept, historical evolution about the procedure and the ramifications of Euthanasia. Aims to demonstrate the legality of the practice of this method to assure the person the exercise of fundamental rights, since the Brazilian legal system does not allow this procedure, both in the current Brazilian Penal Code and in the Draft New Penal Code. Through this study was performed the analysis of concrete case, palliative care as an alternative and related legislation. Portrays about the unavailability of good legal life. It presents the right to the living will and its implantation. Finally, it discusses the right to a dignified death, exercising autonomy over one's own life.
\end{abstract}

Keywords: Euthanasia; Fundamental Rights;. Unavailability legal good life; Dignified Death.

\title{
1. Introdução
}

Com o fim da Segunda Guerra Mundial, devido aos horrores praticados pelos nazistas e a morte de milhares de deficientes, doentes incuráveis e pacientes terminais com a intenção da "purificação da raça", cada Estado buscou inserir, no ordenamento jurídico, o direito à vida e a dignidade da pessoa humana como direitos fundamentais em grau de supervalorização.

Conforme a autora Maria de Fátima Freire de Sá (2005, p. 38-40), a prática da eutanásia existe desde os primórdios da civilização humana. Todavia, o termo "eutanásia" surgiu em 1623, século XVII, proposto por Francis Bacon em sua obra sobre os tratamentos adequados para doenças incuráveis. A palavra Eutanásia vem do grego, eu (boa) e thanatos (morte), que significa "boa morte", ou seja, uma morte livre de sofrimentos.

Após os anos 2000, a prática da eutanásia deixa de ser um tema absolutamente reprovável, pois surge o questionamento sobre o direito da pessoa de dispor da própria vida em casos de doença incurável ou estado terminal. Então, a supervalorização da vida e da dignidade da pessoa humana passa a colidir com outros direitos 
fundamentais, que ocupam no ordenamento jurídico, um mesmo grau de valorização e importância.

Um dos pilares do Estado Democrático de Direito, segundo a Constituição Federal de 1988, é a dignidade da pessoa humana, que começa a ser interpretada de outras formas, como na questão da pessoa morrer com dignidade. Além de ser interpretado de outras formas, esse pilar choca de frente com o princípio da autonomia para o agente dispor sobre a própria vida ou para decidir sobre continuar ou não com tratamentos que prolongam sua morte, fazendo com que perca sua dignidade por chegar ao limite final da vida humana de um modo desumano, degradante, com insuportáveis sofrimentos.

A eutanásia não é abordada como um assunto pacífico seja em qualquer meio de debate, no direito, na religião, na ética e na cultura. No entanto, cada vez mais países adotam legislações sobre a prática, a legalização do procedimento e seus limites, fato que será discutido ao longo desse estudo.

Mediante a tudo que foi exposto, este trabalho tem por objetivo abordar o assunto da eutanásia e sua legalização, diante de toda a problemática envolvida sobre o tema, questionando-se como garantir uma morte digna ao agente que se encontre em estado terminal, em ênfase a valorização da dignidade da pessoa humana e a autonomia do indivíduo dispor de sua própria vida. Ademias o presente estudo apresenta a problemática da eutanásia no ordenamento jurídico brasileiro e os diversos pontos convenientes para se adotar esse procedimento, em face da inexistência de um dispositivo que permita a prática da eutanásia.

\section{Caso de repercussão de eutanásia - Vincent Humbert}

Vincent Humbert, nascido na França, sofreu, em 2000, um acidente automobilístico que o deixou em coma por nove meses. Após o coma, ficou constatado que ele havia ficado tetraplégico, cego e mudo, o único movimento que manteve foi o 
do polegar direito. Através desse movimento conseguiu comunicar-se, por meio de uma pessoa soletrando o alfabeto e pressionando o polegar para demonstrar que queria uma determinada letra (FERREIRA JUNIOR, 2004).

Quando Vincent entendeu esse mecanismo, solicitou aos médicos a prática da eutanásia, para terminar com o sofrimento que tinha, dizendo ser insuportável, todo aquele quadro. O pedido foi recusado pelo fato da França considerar a prática como ilegal. Após o ocorrido, inúmeras solicitações foram feitas, inclusive para sua mãe e também para o presidente da França, através de uma carta. Nessa carta, Vincent pedia para que isentasse de culpa quem o matasse por compaixão e piedade. Por causa de todo o ocorrido, Vincent escreveu um livro, juntamente com um jornalista, com o título "Peço-vos o direito de morrer", lançado em 2003, um dia depois de sua morte. Vincent morreu com altas doses de barbitúricos, administradas pela própria mãe, que não suportava mais ver o próprio filho sofrer e implorar para morrer. (GOLDIM, 2003). As substâncias culminaram em um coma profundo a Vicent e, por decisão dos médicos, os equipamentos que o mantinha vivo foram desligados.

Sua mãe, Marie Humbert, foi presa no mesmo dia, depois solta sendo colocada sob cuidados psiquiátricos. Maria foi processada por auxílio ao suicídio por administrar substâncias tóxicas e apenas em 2006 foi julgado improcedente o pedido, não sendo condenada (GOLDIM, 2003) e (BBC, 2003).

\section{Países que adotaram o procedimento}

Maria de Fátima Freire de Sá (2005, p. 38-40) aponta que a Eutanásia começou a adquirir campo de legislação específica a partir de 2002, com a Holanda como pioneira e influenciadora para os demais países. Alguns países tratam a Eutanásia como aplicação de atenuante, de diminuição de pena, já outros aprimoram o ordenamento jurídico e julgam a prática como perdão judicial ou descriminalização da conduta. 
Após a Holanda tornar-se exemplo de avanço legislativo quanto ao tema em questão, aceitando a liberação do procedimento, o Uruguai foi o primeiro país a legislar especificamente sobre o assunto. A Austrália também foi considerada o país percursor na aprovação da norma que explicitamente legaliza a prática. (Sá, 2005, p. 38-40).

Apesar de o tema Eutanásia existir desde o século XVII, as legislações sobre esse assunto ainda são escassas. Contudo, por mais que ainda falte campo específico sobre, muitos países a aderiram de algum modo. Na Alemanha, por mais que o tema esteja em processo de aprovação desde 2015, autoriza-se a apreciação de casos que exista o consentimento da pessoa. No caso da legislação italiana, o consentimento é necessário para o estabelecimento da atenuante da pena. E, no caso da França, se admite que o doente terminal não tenha tratamento para prolongar a vida, mesmo não estando a eutanásia prevista em lei. (CAVALHEIRO, 2016).

$\mathrm{Na}$ América, o processo de eutanásia ainda é restrito em algumas partes, como, por exemplo, nos Estados Unidos, em que alguns Estados admitem a prática. $\mathrm{Na}$ Colômbia, admite para os que estão em fase terminal e pedem expressamente pelo procedimento (GUIMARÃES, 2009).

Os países que estão em processo de aprovação da Eutanásia são a África do Sul, Alemanha, Canadá, Grã-Bretanha e outros vintes Estados dos Estados Unidos (CAVALHEIRO, 2016).

\section{Eutanásia e suas classificações;}

\subsection{Eutanásia}

A Eutanásia seria uma forma justa de parar com o sofrimento prolongado causado por um quadro irreversível. Trata-se da liberdade que o indivíduo tem de escolher entre sofrer ou não, garantindo a ele uma forma digna de dar fim à própria vida antes da morte natural. Esse termo é denominado como morte piedosa ou 
misericordiosa, pois o indivíduo está sofrendo e existem métodos para que esse sofrimento cesse, uma vez que não há possibilidade de cura.

O termo eutanásia é relatado por Roxin como "a ajuda prestada a uma pessoa gravemente doente, a seu pedido ou de pelo menos em consideração à sua vontade presumida, no intuito de lhe possibilitar uma morte compatível com a sua concepção de dignidade humana" (GARCIA apud ROXIN, 2010).

Para que o procedimento eutanásico ocorra é necessário que tenha os seguintes requisitos: que esteja acometido de doença incurável, aquela que seja irreversível e sem esperança de cura ou que esteja em um estado terminal; que exista requisição voluntária e expressa do paciente (consentimento do interessado), de forma que esteja consciente ou de um representante; que a morte seja provocada por uma ação de terceiro, seja por piedade ou compaixão, sendo assim, esses critérios fazem parte de uma motivação humanística do terceiro; e que o sujeito esteja diante de um sofrimento que o faça querer encurtar o período natural da vida.

De acordo com os defensores da eutanásia, cada indivíduo deve ter sua autonomia para a escolha entre a vida e a morte, e ter a escolha de, caso queira a morte, que seja com dignidade. Essa constatação não se refere que a morte tem que ser defendida, no entanto, tem que ser uma escolha para aqueles que a consideram melhor opção ou a única. Logo, a Eutanásia tem que ser um direito, não um dever (CAVALHEIRO, 2016).

Quando uma pessoa passa a ser prisioneira do seu próprio corpo e passa a depender de terceiros para realizar necessidades básicas da vida, ela começa a se questionar sobre a vida, sobre o que está sentindo, seja fisicamente ou psicologicamente, e esses questionamentos levam à vontade de querer uma morte digna e acima de tudo isso, para que pare de sentir dor, de sofrer, pois deixou de ter a vida que sempre levou, não reconhece mais a qualidade de vida que tinha. Existem pessoas que pensam diferente desta constatação, aceitam sobreviver mesmo que com sofrimento, aceitam muitas vezes até servir de cobaia para novos medicamentos, no 
entanto, para aqueles que não pensam diferente dessa constatação, deve-se assegurar o princípio máximo constitucional e a autonomia do indivíduo, uma vez que essa pessoa está cansada de viver.

Por outro lado, há pessoas que são contra o procedimento da eutanásia, seja por questão religiosa, ética, social e até mesmo política. Desse modo, criam conceitos prévios oriundos desses valores, transmitidos de geração por geração, sem um estudo sobre o tema ou no mínimo dar possiblidade de entender de outro ponto de vista. Existem muitos argumentos sobre usurpação do direito à vida humana, devendo só "Deus" ter esse poder ou argumentos como o médico não pode ser juiz da vida ou da morte de alguém. Além disso, muitos justificam esse posicionamento pelo fato que de poderia ocorrer um aumento de mortes que não seriam necessárias, pessoas querendo a morte sem ser devido a uma doença incurável, estado terminal ou muitas sendo mortas para tráfico de órgãos. Portanto, caso reconhecido o direito de morrer, este poderia expandir por campos imprevisíveis (CAVALHEIRO, 2016).

Algumas posições doutrinarias contrárias também ressaltam que a Eutanásia não revela valor moral ou social, não devendo ser considerado homicídio privilegiado ou perdão judicial, que repugna a consciência humana e que configura apologia a um crime.

A Eutanásia pode ser dividida em ativa, que promova a morte mais cedo do que seu curso natural e por meio de ação de terceiro, ou passiva, a qual surge por meio de uma omissão de terceiro e devido a esta omissão, a pessoa tem a morte antecipada. A passiva não é sinônima da Ortotanásia, vez que na passiva, a conduta omissiva antecipa a morte, o que diferente da conduta omissiva da Ortotanásia que não há qualquer antecipação do momento naturalmente certo (GARCIA, 2010).

O médico pratica a Eutanásia como um meio de cura por acabar com o sofrimento e as dores, não de produzir a morte. Não conduz esse procedimento com a intenção de matar o paciente, mas sim com intenção de ser um meio benéfico para os que sofrem. A Eutanásia médica deve ser impune, por isso existe o perdão judicial, não 
tem intenção criminosa e isso significa que não tem dolo. Assim, médico está animado exclusivamente pela vontade de fazer o bem.

\subsection{Distanásia}

O termo Distanásia vem do grego dys (defeituoso) e thanatos (morte) e expressa o emprego de medicamentos para que eliminem as dores. Tem como fim prolongar artificialmente o processo de morte e com ainda mais sofrimento, já que o paciente fica submetido a fios, máquinas, tubos e exposto a reações imprevisíveis, sem perspectiva de cura. Seria o avesso da Ortotanásia, a qual admite a perspectiva de que a morte não é uma doença a ser curada, nem apressada e muito menos prolongada, mas um final previsto no ciclo da vida. Porém, a Distanásia é conhecida como procedimento legítimo do médico, não sendo punível (FARAH, 2011) e (SANCHES, 2014).

Os médicos consideram como algo que sempre pode ser feito pelo paciente, considerando que é necessário manter a vida a qualquer custo, sem levar em conta o que este acha ou sente a respeito, empregando métodos evasivos. Não seguem o limite do bom senso e da dignidade humana.

Esse procedimento pode ser praticado não para preservar o paciente e tentar fazer com que viva o maior tempo possível, mas sim por interesse econômico dos hospitais que encarecem o atendimento médico, entre outras coisas (FARAH, 2011).

\subsection{Ortotanásia}

A Ortotanásia, que vem do grego como orthos (correto) e thanatos (morte), é a morte no tempo certo e o não prolongamento da vida, ou seja, o médico se omite de praticar tratamentos evasivos que prolongam a vida do paciente em estado terminal, sem chance de cura ou até mesmo adiante o momento naturalmente certo da morte, de 
acordo com a vontade dos pacientes ou representantes. O médico apenas ministra os meios e cuidados paliativos, meios que eliminem as dores (CABRERA, 2010).

Ao contrário da Eutanásia passiva, que tem como entendimento o encurtamento da vida, por meio de omissão ou suspensão de medidas médicas, na Ortotanásia, a conduta dos médicos, ou seja, a omissão destes não antecipa a morte, assim como também não a prolonga, ocorrendo a morte no seu tempo natural (FARAH, 2011).

O temor desse procedimento está para os médicos, pois, segundo a legislação brasileira, caso haja omissão, podem praticar o crime de omissão de socorro ou serem julgados pelo Código de Ética Médica. Porém, o médico não prolongar a vida do paciente, não constitui fato punível.

\subsection{Mistanásia}

Esse termo vem do grego mys (rato) e thanatos (morte), o procedimento é conhecido como morte miserável, ocorre em países pobres ou subdesenvolvidos, pois ocorre fora e antes da hora. Muitos pacientes tornam-se vítimas por erros médicos básicos ou, por muitas vezes, não conseguem virar pacientes e ingressar no sistema de atendimento devido a motivos socioeconômicos. Deixam o enfermo padecer a seu próprio sofrimento (FARAH, 2011).

\subsection{Suicídio Assistido}

Ao contrário da Eutanásia, onde a ação que leva à morte é promovida por terceiro, motivado por piedade, no Suicídio Assistido, o próprio interessado age, seria considerado como auto piedade. Em ambos os casos, a morte é provocada para que exista antecipação da vida do momento em que o evento morte ocorreria espontaneamente. 
O interessado tem que possuir condições físicas para agi por si próprio, sem ser representado, como na Eutanásia, contudo, pode ser auxiliado ou observado. Esse terceiro que auxilia pode responder por crime de auxílio ao suicídio (FARAH, 2011).

\section{Cuidados paliativos como alternativa}

Com o avanço da tecnologia foram criados procedimentos tecnológicos, médicos e hospitalares, que alteram notavelmente a evolução das curas. A criação desses procedimentos tem como objetivo adoção de cuidados paliativos, não tem como propósito apressar a morte nem a manutenção da vida, como no caso da Distanásia.

De acordo com a Organização Mundial da Saúde, em 2002, os cuidados paliativos servem para prevenir e aliviar sofrimento por meio de identificação precoce, tratamento da dor e outros problemas não só físicos, como psicológicos, sociais e espirituais. Tem por finalidade uma proporção entre os meios empregados e o resultado que é para surgir, caso não tenha um resultado esperado, as intervenções do cuidado paliativo não são mais obrigatórias.

O cuidado paliativo não se refere somente à doença, mas à pessoa do paciente, leva-se em conta a qualidade de vida da pessoa. O fim maior do cuidado paliativo é a conciliação da solidariedade humana com a qualidade de vida. Ainda assim, as medidas paliativas nem sempre são eficazes e os pacientes continuam a sentir dor com intensidade, sendo a eutanásia uma alternativa optada, para respeitar o direito da pessoa que prefere morrer com a dignidade que resta a ela (FARAH, 2011).

Parte dos médicos acredita que o avanço tecnológico é um complicador, porque é praticado para prolongar a vida de uma pessoa. Mas reconhecem que o cuidado paliativo é um conforto ao paciente, que não opta pela morte, e para o sentimento dos familiares (FARAH, 2011).

\section{Eutanásia no sistema jurídico brasileiro}


No Brasil, as pessoas ainda se respaldam na religião e por esse motivo, temas como morte e eutanásia são censurados. Existe uma tendência no país de tratar a eutanásia apenas nos aspectos morais, éticos e religiosos, não ampliando o tema para situações conflitantes que envolva a vida de uma pessoa e o quanto pode sofrer por causa de uma doença incurável ou um caso de estado terminal (CAVALHEIRO, 2016).

O Código Penal brasileiro, de 1940, não possui uma classificação específica para a eutanásia. Logo, fica compreendida a eutanásia pelo artigo 121, §1ํ do Código Penal, capítulo dos crimes contra a vida, como homicídio privilegiado e nesse dispositivo é irrelevante a vontade da vítima, não alude ao consentimento, mesmo que ela implore pela medida, não descaracteriza a tipicidade da conduta. Desse modo, a legislação brasileira fere o princípio da dignidade da pessoa humana (CAVALHEIRO, 2016).

Art. 121. Matar alguém:

Pena - reclusão, de seis a vinte anos.

Caso de diminuição de pena

$\S 1^{\circ}$ Se o agente comete o crime impelido por motivo de relevante valor social ou moral, ou sob o domínio de violenta emoção, logo em seguida a injusta provocação da vítima, o juiz pode reduzir a pena de um sexto a um terço.

A eutanásia não se enquadra na faculdade proposta pelo Código Penal em seu artigo 23, que trata de fatos praticados pelo agente e que não são considerados como crime.

Art. 23 - Não há crime quando o agente pratica o fato:

I - em estado de necessidade;

II - em legítima defesa;

III - em estrito cumprimento de dever legal ou no exercício regular de direito.

A legislação brasileira não trata o consentimento da vítima como relevante, pois não está expresso no dispositivo, considera relevante o valor moral, a piedade e o impulso humanitário. Por isso, permite a redução da responsabilidade penal que terceiro sofrerá em virtude da prática da eutanásia. Tratar como homicídio privilegiado configura causa de diminuição da pena. Necessário levar em consideração, nesse caso punitivo, que existe diferença entre matar alguém que não queira mais viver e matar alguém sem seu consentimento, desse modo, é necessário o requisito de 
consentimento para terceiro não ser punido. O médico especializado, que seria o profissional adequado para aplicação do procedimento, não tem a vontade de matar o paciente sem motivo algum. O paciente só morre por meio da eutanásia pela justificativa de estado de necessidade, e não porque o médico simplesmente o matou, a vontade não parte do médico (CAVALHEIRO, 2016).

O princípio da dignidade da pessoa humana, por ser um direito fundamental garantido pela Constituição Federal Brasileira e inerente ao indivíduo, deveria proporcionar autonomia para conduzir decisões pessoais que só a ele pertence o direito. E essas decisões defenderem a prática do ato feita pelo médico, considerando ato impune, mediante perdão judicial, como no caso do Uruguai.

Além de tudo, a prática da Eutanásia é considerada competência do Tribunal do Júri, ferindo também princípios inerentes à pessoa que praticou a conduta. Está previsto no artigo. $74, \S 1^{\circ}$, do Código de Processo Penal:

$\S 1^{\circ}$ Compete ao Tribunal do Júri o julgamento dos crimes previstos nos arts.

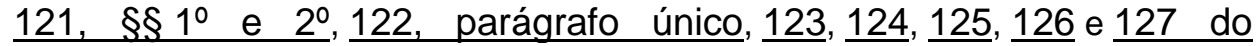
Código Penal, consumados ou tentados.

Existem casos no Brasil em que médicos antecipam o óbito sem o consentimento do paciente. Esses casos não estão atrelados ao instituto da Eutanásia, pois não seguem nenhum dos requisitos previstos para a prática. São casos de homicídio qualificado, previsto no art. 121, §º, incisos II, III, IV, do Código Penal.

Há na resolução 1.805/2006 do Conselho Federal de Medicina, em seu artigo 1ํำ a permissão do procedimento por vontade da pessoa ou de seu representante legal. A resolução permanece válida, de acordo com o poder judiciário.

A escassez de debates sobre eutanásia faz-se essencial observar sua demanda prática, uma vez que não aponta que há a inexistência de procedimentos que agilizem a morte de pacientes em hospitais brasileiros. Sendo assim, necessária a regulamentação para a segurança do indivíduo, da família e do médico que realizará o procedimento. 
No ordenamento brasileiro existiu um projeto de lei o 125/1996, atualmente arquivado, que autorizava a prática da morte sem dor nos casos que especifica. Como, por exemplo, desligamento dos aparelhos do paciente que teve morte cerebral. Ademais, existe na lei do Estado de São Paulo, oㅜ 10.241/1999, em seu artigo 2º a disposição de que o usuário do serviço de saúde de São Paulo pode recusar tratamentos dolorosos ou extraordinários para o prolongamento da vida, reafirmando a tese de que deve respeitar a manifestação de vontade do indivíduo, em respeito ao princípio da dignidade da vida humana.

A autora Maria de Fátima Freira de Sá, em seu livro "Direito de morrer", indaga a respeito de que mesmo possuindo regras expressas no Código Penal brasileiro, se poderia, diante de casos concretos, realizar julgamentos com fundamento em princípios pertencentes à situação, com o objetivo de obter uma decisão justa. Pois, por um lado, o direito penal trata Eutanásia como delito e, por outro, a Constituição Federal garante ao indivíduo o princípio do direito à vida. (SÁ, 2017, p. 3).

\subsection{Anteprojeto do Código Penal}

O projeto de lei sobre a reforma do Código Penal traz determinação expressa da Eutanásia com a justificativa de que a vida é um bem indisponível, mas reconhece a morte e seu curso natural para o paciente, ou seja, caso ele opte pela Ortotanásia, o médico fará os procedimentos e não será punido.

Contudo, caso o paciente opte pela Eutanásia, mesmo que tenha seu consentimento, o médico ainda assim será punido. O maior obstáculo consiste no fato da lei não considerar o contexto fático vivenciado pela sociedade atual e não observar os casos concretos levados ao poder judiciário.

Essa reforma do Código Penal brasileiro tipifica a figura da eutanásia, enquanto estabelece, expressamente, a exclusão de ilicitude da ortotanásia: 
Art. 122. Matar, por piedade ou compaixão, paciente em estado terminal, imputável e maior, a seu pedido, para abreviar-Ihe sofrimento físico insuportável em razão de doença grave:

Pena - prisão, de dois a quatro anos.

$\S 1$ O O juiz deixará de aplicar a pena avaliando as circunstâncias do caso, bem como a relação de parentesco ou estreitos laços de afeição do agente com a vítima. Exclusão de ilicitude

$\S 2^{\circ}$ Não há crime quando o agente deixa de fazer uso de meios artificiais para manter a vida do paciente em caso de doença grave irreversível, e desde que essa circunstância esteja previamente atestada por dois médicos e haja consentimento do paciente, ou, na sua impossibilidade, de ascendente, descendente, cônjuge, companheiro ou irmão.

O caput do artigo relata a prática da Eutanásia. Apresenta a palavra "paciente", fica, assim, entendido que este está sob os cuidados de um médico. Cita somente "paciente em estado terminal", não considerando o paciente com doença incurável.

A pena do caput prevista no anteprojeto, ao contrário do código vigente que prevê a pena do homicídio privilegiado, alterou a punição pela prática da eutanásia para pena de prisão de dois a quatro anos. A princípio a legislação aparenta uma redução bem significativa no sistema legislativo brasileiro, porém, pena de dois a quatro anos para quem praticou o ato de Eutanásia, ainda que nesse caso seja o médico, por causa de um pedido de seu paciente é ainda se mostra excessiva.

O parágrafo primeiro estabelece o perdão judicial, o qual será avaliado pelo juiz por meio das circunstâncias do caso, relação de parentesco ou laço de afeição entre paciente e o autor (no caso, o médico). Este é muito satisfatório para o sistema jurídico brasileiro, uma vez que vivemos em uma sociedade ainda muito religiosa, tradicional. Aliás, além de prever o perdão judicial, evita a frustação da pessoa que praticou o procedimento da eutanásia de ser julgada no Tribunal do Júri, porque não chega a essa fase no processo.

Todavia, o obstáculo desse dispositivo é saber como que o juiz avaliará tais casos e situações, por meio de quais provas seria feita a análise, seria somente a prova testemunhal o suficiente ou precisaria de provas documentais, expressas sobre 0 ocorrido. 
Por último, o parágrafo segundo, que dispõe sobre a exclusão de ilicitude no caso da Ortotanásia, reconhece que o paciente sofre de doença grave irreversível e devido à resolução do Conselho Federal de Medicina, o médico pode suspender ou limitar, de acordo com a vontade do paciente, o tratamento. Nesse caso, não identifica o paciente em estado terminal, apenas usa a expressão "sofre de doença grave irreversível". Por isso, torna-se incertas algumas questões sobre o tema, como, por exemplo, enquadraria ou não o termo "paciente em estado terminal", caso não enquadrasse, para o paciente em estado terminal não seria possível a Ortotanásia. Além disto, por qual motivo excluir a ilicitude da Ortotanásia e não da Eutanásia, pois em ambos os casos o paciente sofre, consente com a prática.

\subsection{Possível implementação da eutanásia}

Lei que regularizasse a possibilidade de o paciente em estado terminal ou doença incurável por fim à sua vida por um meio digno conduzido por um médico. A legislação poderia especificar em que casos ocorreriam, se em casos de sofrimento físico ou também de sofrimento mental, que seria comprovado por médico separado, não aquele que faria a eutanásia.

Os médicos em casos que não achem necessária ou ainda passível de reversão em procedimentos podem recusar a fazer o procedimento da eutanásia.

Seria necessária a demanda de uma organização institucional para o controle e fiscalização. Além disso, avaliar a conduta do médico sobre o procedimento. O médico deve avisar o quadro clínico do paciente e após sua morte fazer um relatório sobre como os fatos ocorreram.

A lei faria com que o procedimento fosse mais seguro ao indivíduo que quer o procedimento, não seria feito de qualquer forma, além disso, não precisaria ir para outro país para ter o procedimento, próprio Brasil garantiria. 
Um dos maiores pilares do Estado Democrático de Direito é a dignidade da pessoa humana, assim, deve-se respeitar a prática desse procedimento, como forma de alternativa àquelas pessoas que preferem encurtar a vida a estar sendo obrigada a viver de uma forma não digna. Como ocorreu no caso concreto relatado anteriormente, dado que, se houvesse a legalização na França, no mínimo sobre casos específicos, Vincent não passaria toda a angústia por anos.

O fato da criação da lei não significa que todos devam aceitar ou que todo paciente incurável ou em estado terminal tenha que se submeter ao procedimento, no entanto, é uma garantia àqueles que optem pela eutanásia. Tal ideia sobre a lei decorre da autora Carmela Marcuzzo do Canto Cavalheiro, que relata sobre esse tema em seu artigo "A tolerância nos Países Baixos e o debate no Brasil: aspectos jurídicos" e como esse método funciona nos países relatados.

\section{Indisponibilidade do bem jurídico vida}

A Constituição Federal, de 1988, prevê no art. 1ํ, que o Estado Democrático de Direito tem como fundamento a dignidade da pessoa humana. No art. 5ำ prevê a inviolabilidade do direito à vida e à liberdade, e em seu inciso três descreve que ninguém será submetido a tratamento desumano ou degradante.

A vida é um direito indisponível tutelado pela Constituição Federal. Sendo assim, o indivíduo tem direito de dispor da vida, pode existir uma flexibilização e quais as limitações?

O Estado quer que o indivíduo tenha todos os meios de cura possíveis, mas existem casos em que não há cura e o paciente sofre com dores, com cansaço de se manter vivo, torna-se desgastante e inviável. Surge, assim, contraste entre a autonomia do Estado com o direito da liberdade individual, integridade da pessoa humana e sua dignidade. 
Vida digna não é sinônima de viver muito ou o máximo que conseguir prolongála, viver com todas as dores e sofrimentos causados por determinada doença, mantendo-se ligada a aparelhos ou até mesmo sem eles, mas dependendo da boa vontade de terceiros para tentar possuir condição normal de vida (FARAH, 2011).

O indivíduo tem direito de dispor sobre sua vida a partir do momento em que não leva mais a mesma vida sã e sadia, atrelada tanto à saúde corporal, quanto mental. $\mathrm{Na}$ ocasião em que não possui mais o mesmo parâmetro de vida, comparado às pessoas que não estão com doenças incuráveis ou não estão em estado terminal, a garantia da efetividade do princípio da igualdade entra conflito. Por isso, para garantir referida efetividade é necessário ter a liberdade de escolha para os indivíduos que não estão em "pé de igualdade" (SÁ, 2005, pg. 58 e 59).

Por ser um direito constitucionalmente garantido, o direito a viver a vida não pode transformar-se em dever de viver, conforme relata Maria de Sá, em sua obra "Direito de morrer". A indisponibilidade da vida necessita, no caso concreto, facultar à pessoa a autonomia da sua própria vida, vez que se encontra em fase terminal ou doença incurável.

Desse modo, há, tradicionalmente, uma corrente que sustenta que a vida humana constitui bem jurídico de titularidade social, não individual, e o princípio da indisponibilidade da vida é consequência desta afirmação. Contemporaneamente, há o surgimento de outra corrente, contrária à primeira, vez que afirma a disponibilidade da vida, que dá ao seu titular a liberdade de disposição (SÁ, 2005, p. 132 e 133).

$O$ caso de Vincent Humbert encontra-se nesse conflito, porque a lei condena a prática da eutanásia em razão do direito à vida, mas por outro lado, tem-se o princípio fundamental da dignidade da pessoa humana. A maior questão para o Poder Judiciário francês, tanto para o caso do Vincent, quanto para o caso de sua mãe que foi processada, foi se a norma emanada deve ser cumprida independentemente de qualquer valoração, flexibilização, independentemente de causar uma injustiça. Ou, 
dependendo do caso concreto, deve-se o jurista refletir sobre o ocorrido e ponderar lei com princípios.

A interrupção de uma vida sofrida, considerada um fardo pela própria pessoa, pelo fato de não conseguir se locomover, não enxergar, não falar, a não ser através do seu dedo, não seria um ato reprovável ao direito. A dignidade da pessoa humana é um princípio imponderável, fato pelo qual dá-se o entendimento oponível inclusive ao direito à vida, que por muitas vezes despreza a qualidade de vida.

O objetivo não é banalizar a vida, mas garantir à pessoa os direitos que the cabem mediante a legislação pátria. Cabe ao Estado, assim, intervir para assegurar o melhor modo da prática, assistência ao paciente e impedir abusos de poder sob o paciente. Não cabe ao Estado decidir sobre o que a autonomia da pessoa frente à sua condição de sofrimento.

\section{Testamento vital: direito a morte e autonomia}

Testamento deriva da expressão "testatio mentis", que significa atestação da vontade. Segundo os doutrinadores civilistas, testamento é ato unilateral, personalíssimo, gratuito, solene e revogável. O direito de testar decorre do direito da personalidade, o qual a pessoa defende o que é lhe é próprio, como a integridade física, moral e intelectual. Sendo assim, o testamento vital também decorre do direito da personalidade (SANCHES, 2014, p. 287-307).

O testamento vital permite, por meio de um documento, que a pessoa deixe a sua vontade expressa a respeito da suspenção de aparelhos e procedimentos como reanimação ou cirurgia, ou seja, um documento que dispõe da própria vida. A pessoa tem que realizar o testamento em uma situação de lucidez mental para que seja levado em conta. Tem como natureza a antecipação para que a pessoa tenha uma morte digna, aplicando-se sobre uma condição terminal, estado de permanente inconsciência ou um dano cerebral irreversível (CAVALHEIRO, 2016). 
Por outro lado, esse documento pode ser usado para que o paciente expresse a vontade de usar aparelhos e obter todos os procedimentos para que o mantenha vivo (CAVALHEIRO, 2016).

Não existe legislação específica para sua formalização, por isso, para que possa tentar comprovação judicialmente, é necessária a manifestação de vontade, e que seja legítima e eficaz, escrita e específica. No entanto, por mais que não exista, no Brasil, regulamentação sobre o testamento vital, devido à força dos princípios da autonomia privada e da dignidade da pessoa humana, admite-se a validade do documento.

As maiores dúvidas sobre esse documento é o momento em que o indivíduo o fez, casos em que pode não estar totalmente lúcido, com capacidade reduzida ou casos em que a doença já havia fragilizado o modo de pensar, a verdade de fato sobre o que quer. Por isso, necessário ser feito de modo prévio.

Essa forma de documento asseguraria o consentimento da vítima, protegendo sua vontade e autonomia, e por consequência funcionaria como documento para exclusão da responsabilidade penal, civil e administrativa do profissional que praticou a eutanásia ou qualquer outro procedimento que se refere à vida de terceiro.

9. Direito de morrer com dignidade

A morte é um estágio da vida que todos estarão diante dela algum dia. Apesar disso, as pessoas que possuem uma doença incurável ou estejam em um estado terminal intensificam ainda mais essa fase da vida e nem todas aceitam facilmente tal fato, pela situação de passarem por esse estágio de uma forma que prolongue sua dor e sofrimento. Muitas sentem raiva, negam a doença ou estado que se encontram, ficam depressivas por estarem conscientes do que está acontecendo, barganham por meio da religião um meio de prolongar a vida sem sofrimento e, por fim, aceitam (HEIDY, 2010).

O tema é discutido desde os povos antigos, no entanto, o Brasil não possui, como outros países, uma lei específica que claramente verse sobre o direito à morte digna, que é a extensão do princípio da dignidade da pessoa humana. 
Morrer com dignidade significa que o paciente que está sofrendo possa ter como garantia o respeito, tanto perante a família quanto a ele mesmo em relação ao estado que se encontra. A pessoa que está nessa condição pode escolher, diante a autonomia perante seu corpo, o quanto quer viver, seja por menos tempo, mas com uma qualidade de vida digna, sem tratamento degradante ou por prolongar tudo o que passa como a dor, o sofrimento e a angustia (HEIDY, 2010) e (GUIMARÃES, 2009).

O direito à morte digna acomoda vários princípios como autonomia da vontade, a liberdade e, principalmente, a dignidade da pessoa humana, que compreende que o ser humano não deve estar subordinado àquilo que o desonre, que faça prolongar sua agonia.

Evidentemente que, uma pessoa em seu estado normal, sem doenças, sem problemas, sem estar em estado do fim da vida, não desejaria abreviar a morte, pois a vida é um direito inerente à pessoa e, sendo assim, esta não quer acabar com sua própria vida. Contudo, caso o paciente esteja em estágio sem cura, sofrendo e sentindo insuportáveis dores, que impendem uma qualidade digna de vida, ele tem o direito de abreviar o vim da vida se assim desejar. O fato de abreviar é fundamentado na busca da dignidade da pessoa humana no estágio final do período vital. Sendo assim, para a pessoa chegar ao estágio final da vida e querer morrer é porque não acha mais terrível esse ato, devido à aceitação, pois para ela o sofrimento é o estágio em si, que pode ser prolongado, com dores e sofrimentos.

Por isso, o direito de morrer dignamente está vinculado à prática da Eutanásia. Muitas vezes o paciente não tem como agir de modo sozinho e dessa forma, há a importância de ter o resguardo à dignidade e a importância do consentimento da pessoa para que seja exercido o direito mencionado. 


\section{Conclusão}

Apesar de a vida ser um bem jurídico protegido constitucionalmente, esta não pode ser resumida a um ordenamento jurídico protegido por um ente público que queira prolonga-la, não pode ser transformada em um dever viver e sim permanecer como direito de viver. Esse direito significa viver bem, de forma digna.

Evidentemente que o ordenamento jurídico deverá considerar o direito a vida indisponível quando a pessoa estiver com o direito de viver pleno, com vida digna, sem doença incurável ou estado terminal, ou algo grave que leve essa pessoa a não querer mais viver.

Caso o paciente opte pela morte por meio da eutanásia, o Estado não pode intervir na decisão, mas o que deve fazer é interferir para fiscalizar o procedimento para ver se cumpriu todos os requisitos, garantia de assistência médica, impedir abuso de poder e violação de direito. A dificuldade, no Brasil, é que o ordenamento jurídico não legaliza a eutanásia e muito menos conferem oportunidades para casos específicos. $O$ Estado pode criar limitações, condições específicas e restritas, que sigam técnicas expressas e, assim, garantir a morte digna para o paciente, concretizando o princípio da dignidade da pessoa humana.

Além da mobilização do Estado para o procedimento da eutanásia, é necessário que dê a devida importância ao testamento vital, já que é considerado um documento válido para o consentimento do paciente, no qual a pessoa possa, antecipadamente, exprimir sua vontade quanto aos tratamentos que pode sofrer no estado em que não estiver consciente mais ou que não consiga distinguir certas coisas.

O consentimento é o maior requisito apresentado para esse método ser eficaz, uma vez que trataria da vontade do próprio paciente sobre qualquer ação do médico e, ainda, funcionaria como causa de excludente e antijuridicidade, suprimento a responsabilidade penal, civil e administrativa do profissional que apenas aplicou 0 procedimento por piedade, por vontade do paciente de acabar com a angústia e o sofrimento. O procedimento, nesses casos, é visto pelo paciente como cura para a vida 
que não Ihe faz mais sentido, como no caso do Vincent Humbert, uma pessoa que sofreu severamente devido ao Estado não conceder a eutanásia tão implorada por ele e seus familiares, uma vez que estava tetraplégico, cego e mudo.

A legalização ou a descriminalização do procedimento da eutanásia não significa que todos os indivíduos sejam favoráveis e devam optar por este procedimento, e aceita-lo. Entretanto, garante a liberdade, para aqueles que entendam como um meio digno de colocar fim ao sofrimento, de praticar os meios pertencentes à eutanásia. Por isso, há a necessidade de um respaldo legal para uma situação de vivência cotidiana, ter a liberdade de escolha como requisito fundamental para a prática de eutanásia para pessoas com quadros clínicos terminais ou incuráveis e que seja realizada de um modo seguro, por meio de um médico especialista.

\section{REFERÊNCIAS}

BRASIL, Constituição da República Federativa, de 05 de outubro de 1988. Disponível em < http://www.planalto.gov.br/ccivil_03/constituicao/constituicaocompilado.htm >. Acesso em: 14 out. 2017.

, Decreto lei no 2.848, de 07 de dezembro de 1940. Instituiu o Código Penal. Disponível em < http://www.planalto.gov.br/ccivil_03/decreto-lei/Del2848compilado.htm >. Acesso em: 15 out. 2017.

, Decreto lei no 3.689, de 03 de outubro de 1941. Instituiu o Código de Processo Penal. Disponível em < http://www.planalto.gov.br/ccivil_03/decretolei/Del3689Compilado.htm >. Acesso em: 15 out. 2017.

, Projeto de lei do Senado no 236, 09 de julho de 2012: Novo código penal. Disponível em < http://www25.senado.leg.br/web/atividade/materias/-/materia/106404 >. Acesso em: 15/10/2017.

, Resolução CFM № 1.805, de 28 de novembro de 2006. Instituiu ao médico limitar ou suspender procedimentos e tratamentos. Disponível em < https://sistemas.cfm.org.br/normas/visualizar/resolucoes/BR/2006/1805 >. Acesso em: 21/10/2017.

, Resolução CFM no 1.931, de 17 de setembro de 2009. Instituiu o Código de Ética Médica. Disponível em < https://portal.cfm.org.br/images/stories/biblioteca/codigo\%20de\%20etica\%20medica.pdf >. Acesso em: 21/10/2017. 
CABRERA, Heidy de Avila. Eutanásia: direito de morrer dignamente. 2010. $158 \mathrm{f}$. Dissertação (Mestrado) - Curso de Direito, Centro Universitário Fieo, Osasco, 2010. Disponível em: < http://www.unifieo.br/pdfs/Heidy_de_Avila_Cabrera.pdf>. Acesso em: $09 / 10 / 2017$.

CAVALHEIRO, Carmela Marcuzzo do Canto. A tolerância da eutanásia nos Países Baixos e o debate no Brasil: aspectos jurídicos. Revista Brasileira de Ciências Criminais, São Paulo, v. 126, p.15-36, 2016. Disponível em: < https://bdjur.stj.jus.br/jspui/handle/2011/106905 >. Acesso em: 10/10/2017.

CUIDADOS PALIATIVOS. Disponível em: < http://www2.inca.gov.br/wps/wcm/connect/cancer/site/tratamento/cuidados_paliativos >. Acesso em: 29/10/ 2017.

FARAH, Elias. Eutanásia, Ortotanásia e Distanásia: reflexões básicas em face da ciência médica e do direito. Revista do Instituto dos Advogados de São Paulo, São Paulo, v. 28, p. 131 - 178, 2011. Disponível em: < http://www.revistadostribunais.com.br/maf/app/resultList/document?\&src=rl\&srguid=i0ad 6adc50000016105b373b3201eb630\&docguid=lba23d9902d2f1 1e1860900008517971a \&hitguid=lba23d9902d2f11e $1860900008517971 \mathrm{a} \&$ spos $=2 \&$ epos $=2 \& \mathrm{td}=268 \&$ context $=7$ \&crumb-action=append \&crumblabel=Documento\&isDocFG=true\&isFromMultiSumm=true\&startChunk=1\&endChunk=1 >. Acesso em: 10/10/2017.

FERREIRA JÚNIOR, Celso Rodrigues. O caso Vincent Humbert: a abordagem positivista e a necessidade de ponderação. Revista Jus Navigandi, ISSN 1518-4862, Teresina, ano 9, n. 382, 24 jul. 2004. Disponível em: <https://jus.com.br/artigos/5501>. Acesso em: 19/10/2017.

FRANCESA ajuda filho tetraplégico e cego a morrer. Disponível em: < http://www.bbc.com/portuguese/noticias/story/2003/09/030926_eutanasia2mtc > . Acesso em: 19/10/2017.

GARCIA, Iberê Anselmo. Aspectos Médicos e Jurídicos da Eutanásia. Revista dos tribunais - Doutrinas Essenciais de Direito Penal, São Paulo, v. 5, p. 459, 2010. Disponível em: < http://www.revistadostribunais.com.br/maf/app/widgetshomepage/resultList/document?\& src=rl\&srguid=i0ad82d9a0000015f7c5398cb2d485935\&docguid=le9306560f25111 dfab6 f010000000000\&hitguid=le9306560f25111dfab6f010000000000\&spos=22\&epos $=22 \&$ td $=26 \&$ context $=101 \&$ crumb-action $=$ append $\&$ crumblabel=Documento\&isDocFG=false\&isFromMultiSumm=true\&startChunk=1\&endChunk=1 >. Acesso em: 09/10/2017. 
GOLDIM, José Roberto, Caso Vincent Humbert: eutanásia ativa voluntária. Disponível em: < https://www.ufrgs.br/bioetica/humbert.htm >. Acesso em: 19/10/ 2017.

GUIMARÃES, Marcello Ovidio Lopes. Eutanásia: novas considerações penais. 2009. Tese (Doutorado em Direito Penal) - Faculdade de Direito, Universidade de São Paulo, São Paulo, 2009. doi:10.11606/T.2.2009.tde-07072010-151229. Acesso em: 09/10/2017.

JÚNIOR, Eudes Quintino de Oliveira. A Eutanásia e a Ortotanásia no novo código penal. Revista dos Tribunais, São Paulo, v. 931, p. 241, 2013. Disponível em: < http://www.revistadostribunais.com.br/maf/app/widgetshomepage/resultList/document?\& srC=rl\&srguid=i0ad82d9a0000015f7c5398cb2d485935\&docguid=If5f16e30f25011 dfab6f $010000000000 \&$ hitguid=lf5f $16 \mathrm{e} 30 \mathrm{f} 25011 \mathrm{dfab6f010000000000 \& spos}=11 \& \mathrm{epos}=11 \& \mathrm{td}=$ $26 \&$ context $=101 \&$ crumb-action $=$ append\&crumblabel=Documento\&isDocFG=false\&isFromMultiSumm=true\&startChunk=1\&endChunk=1 >. Acesso em: 09/10/2017.

PEREIRA, Jeferson Botelho. Inovação do Projeto de Lei no 236/2012 para o novo Código Penal. Disponível em: < https://jus.com.br/artigos/48343/inovacoes-do-projetode-lei-n-236-2012-para-o-novo-codigo-penal-brasileiro >. Acesso em: 16/10/2017.

REVISÃO, Código de Ética Médica. Disponível em < http://www.rcem.cfm.org.br/index.php/cem-atual >. Acesso em: 21 de outubro, 2017

SÁ, Maria de Fátima Freire de. Direito de morrer: Eutanásia, Suicídio Assistido. 2. ed. Belo Horizonte: del Rey, 2005. 184 p.

SANCHES, Vladia Maria de Moura Soares. O testamento vital e o princípio da dignidade da pessoa humana. Revista de Direito Constitucional e Internacional, São Paulo, v. 87, p. 287 - 307, 2014. Disponível em: <

http://www.revistadostribunais.com.br/maf/app/widgetshomepage/resultList/document?\& src=rl\&srguid=i0ad82d9b0000015f7c6bb0de8eb629c9\&docguid $=18 d 4940 \mathrm{e} 000 \mathrm{e} 011 \mathrm{e} 49 \mathrm{a}$ $41010000000000 \&$ hitguid $=18 \mathrm{~d} 4940 \mathrm{e} 000 \mathrm{e} 011 \mathrm{e} 49 \mathrm{a} 41010000000000 \&$ spos $=12 \&$ epos $=12$ $\& \mathrm{td}=26 \&$ context $=257 \&$ crumb-action $=$ append \&crumblabel=Documento\&isDocFG=false\&isFromMultiSumm=true\&startChunk=1\&endChunk=1 >. Acesso em: 09/10/2017. 